\title{
FRACIONAMENTO DE MANGANÊS ACUMULADO NOS TECIDOS DE MUDAS DE CARAMBOLEIRA ${ }^{(1)}$
}

\author{
Amanda Hernandes ${ }^{(2)}$, Jairo Osvaldo Cazetta ${ }^{(3)}$, William Natale $^{(4)}$, \\ Danilo Eduardo Rozane ${ }^{(5)}$, Henrique Antunes de Souza ${ }^{(6)}$ \& Liliane \\ Maria Romualdo ${ }^{(7)}$
}

\begin{abstract}
RESUMO
A caramboleira (Averrhoa carambola) tende a acumular grande quantidade de Mn nos seus tecidos, mas são escassas as informações sobre a forma como o excesso desse nutriente permanece na planta. Com o objetivo de contribuir para o esclarecimento desse aspecto, neste trabalho foram cultivadas mudas de caramboleira em solução nutritiva de Furlani (1999) com concentrações crescentes de $M n\left(0 ; 0,5 ; 25\right.$; e $50 \mathrm{mg} \mathrm{L}^{-1}$ de $\left.\mathrm{Mn}\right)$, e aos 30, 60, 90 e 120 dias os tecidos de caule, folha e raiz foram colhidos e submetidos a uma sequência de soluções extratoras: água, DTPA (ácido dietilenotriaminopentacético) e $\mathrm{HCl}$ (ácido clorídrico) $1 \mathrm{~mol} \mathrm{~L}^{-1}$, com posterior determinação da quantidade de Mn nos extratos e nos tecidos remanescentes. Foram encontrados teores crescentes de Mn nos extratos de água, DTPA e $\mathrm{HCl} 1 \mathrm{~mol} \mathrm{~L}^{-1}$. A maior parte (cerca de 50 \%) do Mn permaneceu no tecido vegetal, mesmo após subsequentes extrações com as diferentes soluções extratoras, indicando que essa parte está fortemente ligada aos tecidos. Os maiores teores de Mn foram encontrados nas raízes e, os menores, no caule e nas folhas, sugerindo que a caramboleira tende a fixar o Mn nas raízes, possivelmente como mecanismo para limitar o transporte para a parte área, evitando a intoxicação da planta.
\end{abstract}

Termos de indexação: Averrhoa carambola, caramboleira, tolerância, micronutrientes, manganês.

(1) Parte da Dissertação de Mestrado do primeiro autor apresentada ao Programa de Pós-Graduação em Agronomia - Ciência do Solo, Universidade Estadual Paulista - FCAV/UNESP, Campus Jaboticabal. Recebido para publicação em 17 de agosto de 2010 e aprovado em 20 de julho de 2011.

(2) Doutoranda do Programa de Pós-Graduação em Agronomia, Produção Vegetal, no Departamento de Solos e Adubos, Universidade Estadual Paulista, Faculdade de Ciências Agrárias e Veterinárias - FCAV/UNESP. Via de Acesso Prof. Paulo Donato Castellane s/n, CEP 14884-900 Jaboticabal (SP). Bolsista da CAPES. E-mail: amahernandes@hotmail.com

(3) Professor Adjunto do Departamento de Tecnologia, FCAV/UNESP. E-mail: cazetta@fcav.unesp.br

(4) Professor Adjunto do Departamento de Solos e Adubos, FCAV/UNESP. Bolsista PQ do CNPq. E-mail: natale@fcav.unesp.br

(5) Professor da UNESP/Campus Experimental de Registro. Rua Nelson Brihi Badur, 430, CEP 11900-000 Registro (SP). E-mail: danilorozane@registro.unesp.br

(6) Pesquisador da Embrapa Caprinos e Ovinos. Fazenda Três Lagoas, Estrada Sobral-Groaíras, Km 04 s/n, Zona Rural, CEP 62010-970 Sobral (CE). E-mail: henrique@cnpc.embrapa.br

(7) Doutoranda do Programa de Pós-Graduação em Zootecnia, Universidade de São Paulo, Faculdade de Zootecnia e Engenharia de Alimentos - FZEA/USP. Av. Duque de Caxias 255, CEP 13635-900 Pirassununga (SP). E-mail: lilianeromualdo@yahoo.com.br 


\title{
SUMMARY: FRACTIONATIONOF MANGANESE ACCUMULATED INTISSUE OF STAR FRUIT PLANTLETS
}

\begin{abstract}
Star fruit (Averrhoa carambola) plants tend to accumulate significant amounts of Mn in their tissues. However, information regarding the form in which the plant stores the excess is scarce. For a deeper understanding of this aspect, star fruit plantlets were grown in nutritive solutions of Furlani (1999) with increasing levels of $M n\left(0,0.5,25\right.$ and $\left.50 \mathrm{mg} \mathrm{L}^{-1}\right)$, and after 30, 60, 90 and 120 days the tissues were collected and subjected to a sequence of extracting solutions: water, DTPA (diethyltriaminepentacetic acid), and $\mathrm{HCl}$ (chloridric acid) $1 \mathrm{~mol} \mathrm{~L} \mathrm{~L}^{-1}$. Then, $M n$ was determined in the extracts and remaining tissues. Increasing $M n$ concentrations were found in the extracts with water, DTPA and $\mathrm{HCl}$. The greatest part of $\mathrm{Mn}$ (about $50 \%$ ) was detected in the remaining tissues, even after successive extractions with the different solutions, suggesting a strong linkage to plant tissues. Highest Mn concentrations were found in the roots, then the stalk and the leaf tissues, suggesting that star fruit plants tend to fix $M n$ in the root tissues, which is possibly a defense mechanism to limit Mn transport to the aerial part, to avoid plant intoxication.
\end{abstract}

Index terms: Averrhoa carambola, star fruit, tolerance, micronutrients, manganese.

\section{INTRODUÇÃO}

As principais áreas de produção de carambolas estão localizadas em regiões caracterizadas por solos ácidos, com baixa saturação por bases e frequentemente com $\mathrm{Al}$ e $\mathrm{Mn}$ em quantidades altas (Prado \& Natale, 2008), limitando o desenvolvimento normal dos vegetais em geral. Porém, elevadas concentrações de $\mathrm{Mn}$ no solo pouco refletem no crescimento e desenvolvimento de caramboleiras em razão, provavelmente, da rusticidade da frutífera, a qual pode ter desenvolvido mecanismos de adaptação e tolerância ao excesso desse nutriente (Prado \& Natale, 2004).

Na literatura há relatos de teores de Mn em folhas de caramboleira variando de 73 a $1.745 \mathrm{mg} \mathrm{kg}^{-1}$ (Silva et al., 1984; Crane, 1998; Prado, 2003; Leal, 2006), os quais são considerados muito altos quando comparados com o Mn e outros micronutrientes em diferentes frutíferas. Os altos teores de Mn encontrados em caramboleiras atingem níveis tão elevados que podem explicar a tolerância dessa frutífera a doenças e pragas (Brown et al., 1984; Graham \& Webb, 1991; Huber \& Keeler, 2006; Sadasivan, 2006; Graham \& Rovira, 2006). Entretanto, são muito escassas as informações sobre a forma na qual o Mn permanece na planta, sendo os poucos resultados disponíveis controversos.

O número de trabalhos que relataram a distribuição do Mn entre os diferentes órgãos da planta é muito restrito. Um desses estudos sugere que os cloroplastos acumulam Mn em maior quantidade que o restante do tecido foliar (Udel’Nova et al., 1976), enquanto outro sugere que não há diferença na distribuição de Mn no tecido foliar (Whatley et al., 1951).

Folhas de plantas de chá com elevados teores de Mn (Quercus mongolica var. grosseserrata, Lindera erythrocarpa, Rhus trichocarpa, Ilex crenata var. paludosa, Acer sieboldianum, Acanthopanax sciadophylloides, Clethra barbinervis, Pieris japonica e Rhododendron semibarbatum), porém em níveis não tóxicos, apresentaram maior acúmulo de Mn na epiderme em relação às células parenquimáticas. $\mathrm{O}$ Mn pareceu acumular-se mais fortemente nas paredes celulares que no interior das células epidérmicas, onde foi facilmente lavado (Memon et al., 1981), sugerindo que o excesso do elemento estava prontamente disponível nos tecidos, não exercendo qualquer função específica.

Este trabalho objetivou verificar como o $\mathrm{Mn}$ se encontra distribuído nos tecidos de folha, caule e raízes de caramboleiras quando cultivadas por diferentes períodos e com níveis crescentes desse nutriente.

\section{MATERIAL E MÉTODOS}

O experimento foi realizado em casa de vegetação, no período de outubro/2008 a março/2009, na Faculdade de Ciências Agrárias e Veterinária da Universidade Estadual Paulista/Unesp, Campus Jaboticabal, situada no município de Jaboticabal, SP, com coordenadas geográficas de $21^{\circ} 15^{\prime} \mathrm{S}$ de latitude e $48^{\circ} 18^{\prime}$ $\mathrm{W}$ de longitude e altitude de $575 \mathrm{~m}$.

Foram utilizadas mudas de caramboleira (Averrhoa carambola) cv. BR96 enxertadas sobre portaenxertos obtidos por semente, com a idade de 12 meses após a enxertia, cultivadas anteriormente em substrato comercial.

Antes da aplicação dos tratamentos e após 12 meses de enxertia, as mudas foram mantidas em solução nutritiva completa de Furlani (1999) diluída a 1/4 da concentração usual, durante os primeiros 15 dias, para a adaptação das plantas. Após esse período, as mudas foram submetidas à solução nutritiva completa e sem diluição, com exceção do Mn, que foi empregado 
em diferentes doses, conforme as quantidades estabelecidas em cada tratamento.

$\mathrm{O}$ experimento constou de 16 tratamentos compostos de quatro doses de $\mathrm{Mn}$ e quatro coletas de plantas, num total de 48 parcelas. O delineamento experimental adotado foi o de blocos ao acaso com três repetições, em esquema fatorial $4 \times 4$. Cada unidade experimental consistiu de um vaso de $5,5 \mathrm{~L}$ de solução nutritiva com duas mudas de caramboleira. As doses de $\mathrm{Mn}$, na forma de $\mathrm{MnSO}_{4}$, foram, em mg L-1: $\mathrm{D}_{0}=$ zero; $\mathrm{D}_{1}=0,5 ; \mathrm{D}_{2}=25$; e $\mathrm{D}_{3}=50$. A dose $\mathrm{D}_{1}$ foi considerada a dose-padrão, de acordo com a concentração de Mn contida na solução nutritiva proposta por Furlani (1999), sendo também a recomendada por Rozane et al. (2007) como a mais adequada para a condução de mudas de caramboleira. As doses $\mathrm{D}_{2}$ e $\mathrm{D}_{3}$ foram estabelecidas a partir de ensaios preliminares, em que se foram testadas doses crescentes de Mn em solução nutritiva com mudas de caramboleiras até que as plantas apresentassem efeitos visuais de excesso desse nutriente, caracterizados por clorose internerval nas folhas mais novas, com reticulado fino das nervuras apresentando menor espessura laminar e salpicos adensados de minúsculas pontuações escuras por todo o limbo das folhas mais velhas. As coletas de plantas para análise foram realizadas aos 30, 60, 90 e 120 dias após a aplicação dos tratamentos.

O manejo da solução nutritiva ao longo do período de estudo foi realizado pelo monitoramento do $\mathrm{pH}$ em dias alternados, por meio de um medidor portátil (PG 1400), sendo ajustado a 5,0 $\pm 0,5$, usando-se solução de $\mathrm{NaOH}$ ou $\mathrm{HCl} 0,1 \mathrm{~mol} \mathrm{~L}^{-1}$; e também pela condutividade elétrica, que foi mantida entre 2,0 e $2,4 \mathrm{dS} \mathrm{m}^{-1}$, por meio de condutivímetro portátil (CG 220). A reposição da água evapotranspirada foi realizada com água destilada e deionizada, com a troca completa da solução a cada 30 dias. A solução nutritiva foi oxigenada continuamente no período diurno, ao longo de todo o experimento.

Em cada coleta, as plantas foram divididas em folhas, caule e raízes, em sua totalidade. Logo depois, as estruturas foram lavadas inicialmente com água destilada, em seguida com detergente neutro na concentração de $0,1 \%$, depois com solução de $\mathrm{HCl}$ na concentração de $3 \%$ em volume e, por último, com água destilada e deionizada. Imediatamente após a lavagem, as estruturas foram colocadas em sacos de papel e postas para secar em estufa de circulação forçada de ar, com temperatura controlada $\left(65-70^{\circ} \mathrm{C}\right)$, até massa constante. As diferentes partes das caramboleiras foram pesadas, moídas, passadas em peneira de $2 \mathrm{~mm}$ e armazenadas para as posteriores determinações dos teores de Mn total, seguindo-se o método descrito por Bataglia et al. (1983), o qual consiste na determinação direta do Mn no extrato nítrico-perclórico, após a digestão, em espectrofotômetro de absorção atômica. Além do teor total, as amostras de folhas, caule e raízes foram submetidas à extração sequencial com soluções de crescente poder extrator. Inicialmente, foi realizada a extração com água, visando retirar o Mn solúvel. A seguir foi procedida a extração com uma solução de DTPA, preparada conforme indicações de Raij et al. (2001), a qual foi considerada de capacidade intermediária de eluição do $\mathrm{Mn}$ dos tecidos e, por fim, com $\mathrm{HCl} 1 \mathrm{~mol} \mathrm{~L}^{-1}$, o qual possui grande capacidade de extração de íons trocáveis das amostras, restando o tecido com o $\mathrm{Mn}$ fortemente fixado e que não foi extraído pela sequência citada de extratores. Para tanto, utilizou-se 0,5 g de cada amostra, que foi acondicionado individualmente em cartuchos feitos com papel-filtro, dobrando-se as pontas e amarrando-as, para evitar a perda de material. Cada cartucho foi inserido em um tubo de digestão (tubo de ensaio de $20 \times 250 \mathrm{~mm}$ ). As extrações foram realizadas sequencialmente, uma de cada vez, colocando-se $20 \mathrm{~mL}$ do extrator no tubo de ensaio e mantendo-se por 20 min em banho-maria a $70{ }^{\circ} \mathrm{C}$. Após esse período, a solução foi transferida para outro tubo de ensaio de 20 x $250 \mathrm{~mm}$, limpo e seco. Esse procedimento foi repetido três vezes em um mesmo extrator antes de se proceder ao trabalho com o extrator seguinte. Ao término das extrações, os distintos tubos contendo os extratos das diferentes soluções extratoras foram colocados em bloco digestor regulado para $90{ }^{\circ} \mathrm{C}$ até a completa evaporação da solução, em capela de exaustão de gases. Os resíduos resultantes nos tubos foram submetidos à digestão nítricoperclórica e, em seguida, completado o volume para $50 \mathrm{~mL}$.

Após as extrações consecutivas, os cartuchos contendo as amostras também foram integralmente submetidos à digestão nítrico-perclórica e o extrato, diluído a $50 \mathrm{~mL}$. A seguir, o teor de $\mathrm{Mn}$ em todos os extratos foi determinado em espectrofotômetro de absorção atômica Varian, modelo Spectra A50D.

É importante ressaltar que o esquema de extrações sequenciais usado neste trabalho foi estabelecido a partir de testes preliminares, nos quais também foi testada uma primeira extração com éter etílico, visando determinar o $\mathrm{Mn}$ associado a compostos do extrato etéreo. Porém, não se encontrou Mn nesse extrato. Assim, concluiu-se que o Mn não está associado a compostos lipídicos, e, por isso, optou-se por excluir essa extração da sequência utilizada nas amostras do experimento.

Com os resultados foi calculada a quantidade de Mn extraída na fração de cada extrator, bem como a remanescente nos tecidos após a sequência de extração (denominada neste trabalho fração residual, ou Mn fortemente associado ao tecido vegetal).

Os dados foram submetidos à análise de variância pelo teste F. Para avaliar o efeito dos extratores, foi aplicado o teste de Tukey a $5 \%$, e para avaliar o efeito das doses de $\mathrm{Mn}$ e das épocas de coleta sobre as determinações na planta foi utilizada a análise de regressão polinomial, usando-se o Software AgroEstat (Barbosa \& Maldonado Júnior, 2009). 


\section{RESULTADOS E DISCUSSÃO}

Os teores de Mn determinados nas folhas, caule e raízes das mudas de caramboleira, a partir de seu fracionamento com o uso de diferentes extratores, estão apresentados no quadro 1 . No quadro 2 estão os desdobramentos das interações triplas para doses dentro de cada extrator e de cada época de coleta. Verificaram-se diferenças significativas e interações entre os extratores utilizados, assim como entre as doses de Mn aplicadas, bem como no decorrer das épocas de coleta.

Os teores de Mn obtidos da soma dos fracionamentos (água + DTPA + $\mathrm{HCl} 1 \mathrm{~mol} \mathrm{~L}^{-1}+$ residual) equivalem aos teores encontrados de $\mathrm{Mn}$ total, tanto nas folhas quanto no caule e nas raízes. As médias dos teores de Mn total, considerando-se folhas, caule e raízes e todas as épocas de coleta, foram de 162, 198, 2.095 e $3.370 \mathrm{mg} \mathrm{kg}^{-1}$, nas doses 0 ; 0,5 ; 25 ; e $50 \mathrm{mg} \mathrm{L}^{-1}$, respectivamente. Esses valores foram muito próximos das médias encontradas quando consideradas as somas de todas as frações, os quais foram de 175, 208, 2.127 e $3.419 \mathrm{mg} \mathrm{kg}^{-1}$ de Mn, nas doses de 0; 0,5; 25; e $50 \mathrm{mg} \mathrm{L} \mathrm{L}^{-1}$, respectivamente. Foram verificados aumentos lineares nos teores de Mn nas folhas, no caule e nas raízes com o incremento das doses aplicadas, assim como no decorrer das épocas de coleta das plantas para análise (Quadro 1).

A porcentagem de Mn extraída com água apresentou os menores valores, em comparação com os demais extratores, indicando que pouco Mn está

Quadro 1. Resultados da análise de variância e dados médios da extração de manganês fracionado nas folhas, caule e raízes de mudas de caramboleira cultivadas em hidroponia, em função da aplicação de doses crescentes de manganês

\begin{tabular}{|c|c|c|c|c|}
\hline \multirow{3}{*}{$\begin{array}{l}\text { Extrator (A) } \\
\text { Água }\end{array}$} & \multicolumn{4}{|c|}{ Teor de Mn (mg kg-1 MS) } \\
\hline & Folha & Caule & \multicolumn{2}{|c|}{ Raiz } \\
\hline & $(6,95 \%)$ & $(2,53 \%)$ & $16 \mathrm{~d}$ & $(2,35 \%)$ \\
\hline DTPA & $(10,50 \%)$ & $(12,63 \%)$ & $45 \mathrm{c}$ & $(6,63 \%)$ \\
\hline $\mathrm{HCl} 1 \mathrm{~N}$ & $(22,45 \%)$ & $(19,19 \%)$ & $142 \mathrm{~b}$ & $(20,92 \%)$ \\
\hline Residual & $(60,10 \%)$ & $(65,65 \%)$ & $476 \mathrm{a}$ & $(70,10 \%)$ \\
\hline DMS (5\%) & 17,19 & 4,46 & 11,90 & \\
\hline Teste F & $1039,29 * *$ & $2073,07 * *$ & $4273,79 * *$ & \\
\hline \multicolumn{5}{|l|}{ Doses de Mn (D) } \\
\hline $0 \mathrm{mg} \mathrm{L}^{-1}$ & 18 & 15 & 11 & \\
\hline $0,5 \mathrm{mg} \mathrm{L}^{-1}$ & 19 & 14 & 22 & \\
\hline $25 \mathrm{mg} \mathrm{L}^{-1}$ & 198 & 62 & 282 & \\
\hline $50 \mathrm{mg} \mathrm{L}^{-1}$ & 385 & 106 & 364 & \\
\hline Teste F & $1407,13^{* *}$ & $1329,67^{* *}$ & $3097,59 * *$ & \\
\hline Reg. linear & $4220,93^{* *}$ & $3985,45^{* *}$ & $8699,19^{* *}$ & \\
\hline \multicolumn{5}{|l|}{ Época de coleta (E) } \\
\hline 30 dias & 136 & 44 & 90 & \\
\hline 60 dias & 143 & 49 & 180 & \\
\hline 90 dias & 165 & 52 & 198 & \\
\hline 120 dias & 175 & 53 & 211 & \\
\hline Teste F & $14,91^{* *}$ & $12,53^{* *}$ & $286,04^{* *}$ & \\
\hline Reg. linear & $42,97 * *$ & $15,33^{* *}$ & $696,44^{* *}$ & \\
\hline$A \times D$ & $335,10 * *$ & $427,07 * *$ & $1209,11^{* *}$ & \\
\hline Doses d. água & 29,17 ** & $3,34^{*}$ & $7,64^{* *}$ & \\
\hline Doses d. DTPA & $54,71^{* *}$ & $63,85^{* *}$ & $44,62^{* *}$ & \\
\hline Doses d. HCl $1 \mathrm{~mol} \mathrm{~L}^{-1}$ & $294,75^{* *}$ & $232,45^{* *}$ & $569,96^{* *}$ & \\
\hline Doses d. residual & $2033,81^{* *}$ & $2311,24^{* *}$ & $6102,70 * *$ & \\
\hline$A \times E$ & $4,33^{* *}$ & $6,43^{* *}$ & $162,96^{* *}$ & \\
\hline Extratores d. 30 dias & $221,53^{* *}$ & $451,04^{* *}$ & $202,11^{* *}$ & \\
\hline Extratores d. 60 dias & $205,04 * *$ & $412,57 * *$ & $1254,54^{* *}$ & \\
\hline Extratores d. 90 dias & $292,76^{* *}$ & $583,17^{* *}$ & $1547,60 * *$ & \\
\hline Extratores d. 120 dias & $332,93^{* *}$ & $645,58^{* *}$ & $1758,40^{* *}$ & \\
\hline $\mathbf{D} \times \mathbf{E}$ & $15,26 * *$ & $10,12^{* *}$ & $106,92^{* *}$ & \\
\hline Doses d. 30 dias & $209,24^{* *}$ & $234,17^{* *}$ & $327,36^{* *}$ & \\
\hline Doses d. 60 dias & $284,00 * *$ & $269,87^{* *}$ & $866,04^{* *}$ & \\
\hline Doses d. 90 dias & $436,57 * *$ & $378,76^{* *}$ & $1058,34^{* *}$ & \\
\hline Doses d. 120 dias & $523,10 * *$ & $477,22^{* *}$ & $1166,61^{* *}$ & \\
\hline$A \times D \times E$ & $4,02^{* *}$ & $4,40^{* *}$ & $56,56^{* *}$ & \\
\hline CV (\%) & 20,9 & 17,0 & 13,2 & \\
\hline
\end{tabular}

$* \mathrm{e}^{* *}$ : significativos a $\mathrm{p} \leq 0,05$ e $\mathrm{p} \leq 0,01$, respectivamente. Médias seguidas da mesma letra, na coluna, não diferem entre si a $\mathrm{p}$ $\leq 0,05$, pelo teste de Tukey. 
totalmente livre nos tecidos da planta. Essa fração solúvel pode estar livre no vacúolo, ou participando como ativador enzimático de diversos processos metabólicos no citoplasma ou, então, fazendo parte de compostos solúveis em água, como alguns aminoácidos (Graham et al., 1988; Malavolta et al., 1997; Malavolta, 2006; Sharma, 2006).

A utilização da solução DTPA teve por objetivo extrair o Mn "trocável" dos tecidos, ou seja, o Mn ligado fracamente a compostos insolúveis, não estando totalmente livre. Assim, acredita-se que o extrator DTPA deslocou o Mn desses compostos para a solução. Verificou-se que os teores de Mn obtidos com essa extração foram mais elevados que aqueles extraídos por água, indicando que parte desse nutriente estaria associada a componentes insolúveis dos tecidos (Graham et al., 1988; Malavolta, 2006; Sharma, 2006).

A solução de $\mathrm{HCl} 1 \mathrm{~mol} \mathrm{~L}^{-1}$, utilizada na sequência dos demais extratores, por sua vez extraiu mais $\mathrm{Mn}$, quando comparada às outras duas extrações precedentes (água e DTPA). Acredita-se que essa extração tenha removido o Mn ligado mais fortemente a compostos insolúveis mencionados por Malavolta et al. (1997) e Malavolta (2006), sendo o $\mathrm{Mn}^{2+}$ deslocado pela elevada concentração de $\mathrm{H}^{+}$desse extrator.

A fração residual, quando comparada com os demais extratores, apresentou teores bastante elevados, indicando que a maior porcentagem (superior a $50 \%$ ) do Mn presente nos tecidos está fortemente associada à parte insolúvel, não sendo passível de remoção pelas sucessivas extrações com água, DTPA e $\mathrm{HCl} 1 \mathrm{~mol} \mathrm{~L}^{-1}$. Essa fração corresponde ao $\mathrm{Mn}$ presente nas estruturas de compostos ou fazendo parte de complexos muito estáveis e insolúveis, como algumas proteínas (Malavolta, 2006), sendo pouco provável sua remoção sem o rompimento e a completa destruição desses compostos ou, ainda, fazendo parte das paredes celulares, uma vez que há evidências de que o Mn faz parte da estrutura química da lignina (Graham et al., 1988; Malavolta et al., 1997; Malavolta, 2006; Sharma, 2006).

Desdobrando as interações triplas que ocorreram nas folhas, caule e raízes nas doses de Mn dentro de cada extrator e cada época de coleta, verificou-se que houve aumentos lineares nos teores de $\mathrm{Mn}$ em todos os extratores (água, DTPA, $\mathrm{HCl} 1 \mathrm{~mol} \mathrm{~L}^{-1} \mathrm{e}$ o residual), em cada época de coleta (Quadro 2). No decorrer do tempo em que as plantas permaneceram submetidas aos tratamentos, todos os extratores apresentaram diminuição nos teores de $\mathrm{Mn}$ nas folhas e no caule e aumento dos teores nas raízes, sugerindo um mecanismo de defesa da frutífera ao excesso de $\mathrm{Mn}$ presente na solução nutritiva. É possível que o acúmulo de $\mathrm{Mn}$ nas raízes seja devido a algum mecanismo da planta para evitar o transporte de quantidades excessivas desse nutriente para a parte aérea, visando prevenir a intoxicação das folhas. Tal hipótese se baseia no fato de que os mecanismos de tolerância ao excesso de Mn têm sido associados à

Quadro 2. Equações de regressão e coeficiente de correlação resultantes do desdobramento das interações entre doses, dentro do extrator e época de coleta, para extração de manganês fracionado nas folhas, caule e raízes de mudas de caramboleira cultivadas em hidroponia, em função da aplicação de doses de manganês

\begin{tabular}{|c|c|c|c|c|c|c|}
\hline \multirow{2}{*}{$\mathbf{D} \times \mathbf{A} \times \mathbf{E}$} & \multicolumn{2}{|l|}{ Mn folha } & \multicolumn{2}{|l|}{ Mn caule } & \multicolumn{2}{|l|}{ Mn raiz } \\
\hline & Equação & $\mathbf{R}^{2}$ & Equação & $\mathbf{R}^{2}$ & Equação & $\mathrm{R}^{2}$ \\
\hline & \multicolumn{6}{|c|}{ Doses d. água } \\
\hline 30 dias & $\hat{y}=9,74+0,92 x$ & $\hat{y}=0,93$ & $\hat{y}=2,71+0,11 x$ & 0,88 & $0,70+0,29 x$ & 0,94 \\
\hline 60 dias & $\hat{y}=2,68+0,90 x$ & $\hat{y}=0,97$ & $\hat{y}=1,73+0,08 x$ & 0,91 & $1,67+0,46 x$ & 0,99 \\
\hline 90 dias & $\hat{y}=1,13+1,12 x$ & $\hat{y}=0,99$ & $\hat{y}=1,72+0,09 x$ & 0,91 & $1,21+0,39 x$ & 0,99 \\
\hline \multirow[t]{2}{*}{120 dias } & $\hat{y}=0,53+1,27 x$ & $\hat{y}=0,99$ & $\hat{y}=0,97+0,09 x$ & 0,89 & $\hat{\mathrm{y}}=2,39+0,35 \mathrm{x}$ & 0,95 \\
\hline & \multicolumn{6}{|c|}{ Doses d. DTPA } \\
\hline 30 dias & $\hat{y}=17,18+1,01 x$ & $\hat{y}=0,98$ & $\hat{y}=15,39+0,37 x$ & 0,86 & $\hat{y}=7,34+0,74 x$ & 0,97 \\
\hline 60 dias & $\hat{\mathrm{y}}=11,61+1,41 \mathrm{x}$ & $\hat{\mathrm{y}}=0,98$ & $\hat{y}=9,85+0,29 x$ & 0,95 & $\hat{\mathrm{y}}=13,88+0,88 \mathrm{x}$ & 0,86 \\
\hline 90 dias & $\hat{\mathrm{y}}=8,35+1,60 \mathrm{x}$ & $\hat{y}=0,98$ & $\hat{\mathrm{y}}=5,61+0,51 \mathrm{x}$ & 0,86 & $\hat{y}=11,73+0,96 x$ & 0,91 \\
\hline \multirow[t]{2}{*}{120 dias } & $\hat{y}=5,03+1,77 x$ & $\hat{\mathrm{y}}=0,98$ & $\hat{y}=5,67+0,46 x$ & 0,96 & $\hat{y}=12,36+0,94 x$ & 0,91 \\
\hline & \multicolumn{6}{|c|}{ Doses d. $\mathrm{HCl} 1 \mathrm{~mol} \mathrm{~L}^{-1}$} \\
\hline 30 dias & $\hat{y}=25,27+2,08 x$ & $\hat{y}=0,98$ & $\hat{y}=14,28+0,55 x$ & 0,94 & $\hat{y}=1,31+2,50 x$ & 0,95 \\
\hline 60 dias & $\hat{y}=10,43+3,37 x$ & $\hat{y}=0,97$ & $\hat{y}=7,44+0,68 x$ & 0,97 & $\hat{y}=20,42+0,37 x$ & 0,86 \\
\hline 90 dias & $\hat{y}=5,76+3,92 x$ & $\hat{\mathrm{y}}=0,99$ & $\hat{y}=7,80+0,88 x$ & 0,93 & $\hat{\mathrm{y}}=25,57+3,52 \mathrm{x}$ & 0,92 \\
\hline \multirow[t]{2}{*}{120 dias } & $\hat{y}=5,51+4,08 x$ & $\hat{y}=0,97$ & $\hat{y}=5,63+0,97 x$ & 0,97 & $\hat{\mathrm{y}}=37,37+3,71 \mathrm{x}$ & 0,85 \\
\hline & \multicolumn{6}{|c|}{ Doses d. residual } \\
\hline 30 dias & $\hat{y}=64,78+7,32 x$ & $\hat{y}=0,98$ & $\hat{y}=45,62+2,07 x$ & 0,97 & $\hat{y}=6,95+5,94 x$ & 0,88 \\
\hline 60 dias & $\hat{y}=49,60+7,52 x$ & $\hat{y}=0,98$ & $\hat{y}=28,5+2,29 x$ & 0,98 & $\hat{y}=115,49+10,58 x$ & 0,84 \\
\hline 90 dias & $\hat{\mathrm{y}}=26,46+9,74 \mathrm{x}$ & $\hat{y}=0,98$ & $\hat{\mathrm{y}}=43,39+2,48 \mathrm{x}$ & 0,98 & $\hat{\mathrm{y}}=118,11+11,92 \mathrm{x}$ & 0,88 \\
\hline 120 dias & $\hat{y}=12,24+10,80 x$ & $\hat{y}=0,98$ & $\hat{y}=32,23+2,92 x$ & 0,98 & $\hat{\mathrm{y}}=135,67+12,41 \mathrm{x}$ & 0,88 \\
\hline
\end{tabular}


oxidação desse nutriente nas raízes, à restrição na taxa de absorção pelas raízes e à diminuição no transporte do excesso de Mn para as folhas, bem como à interação com outros nutrientes (Foy et al., 1978; Moroni et al., 2003). Além disso, a exemplo do que acontece com os metais pesados, pode ser que ocorra desintoxicação celular do excesso de Mn por agentes complexantes no sistema radicular (fitoquelatinas, metalotioneínas e nicotianamina) com posterior deposição no apoplasto. Essa deposição no apoplasto ou a estocagem dos complexos pouco móveis no interior dos vacúolos reduziria sua solubilidade e seu transporte ao longo da planta, evitando a intoxicação de tecidos sensíveis como as folhas (Yan et al., 2000; Bidwell et al., 2002; Ducic \& Polle, 2005).

Também, tem sido constatado maior acúmulo de Mn nas raízes de genótipos de outras espécies como arroz e feijão-mungo tolerantes a elevados níveis de Mn, sugerindo que ocorre acúmulo do Mn nas matrizes pécticas das paredes celulares e, ainda, aumento no transporte do Mn para os vacúolos, em virtude da ativação de adenosina trifosfatases (ATP-ases) nas membranas. Isso resulta em sua complexação com ácidos orgânicos, ligação com proteínas específicas, bem como alterações nas estruturas das membranas, que passam a ser menos permeáveis ao $\mathrm{Mn}$, reduzindo sua mobilidade. Tais fatores podem constituir estratégias eficientes de tolerância a elevados níveis desse nutriente no ambiente das raízes (Rout et al., 2001).

\section{CONCLUSÕES}

1. Os teores de $\mathrm{Mn}$ foram crescentes nas extrações sequenciais realizadas com água, DTPA e $\mathrm{HCl}$ $1 \mathrm{~mol} \mathrm{~L}^{-1}$.

2. A maior parte do Mn presente nas folhas, caule e raízes está fortemente ligada aos tecidos.

3. Os maiores teores de Mn encontrados nas raízes, seguidos daqueles em caule e folhas, sugerem que a caramboleira tende a fixar o Mn nas raízes, possivelmente como mecanismo para limitar o transporte do metal à parte área, evitando a fitotoxidez.

\section{AGRADECIMENTOS}

Ao Conselho Nacional de Desenvolvimento Científico e Tecnológico (CNPq), pelo apoio financeiro concedido por meio da bolsa de Pós-Graduação (Processo 136327/2008 7); e aos produtores Sr. José Mauro da Silva e Sr. João Mateus da Silva, do viveiro de mudas do Sítio São João, Taquaritinga, Estado de São Paulo, pelo fornecimento das mudas de caramboleira para a realização deste estudo.

\section{LITERATURA CITADA}

BARBOSA, J.C. \& MALDONADO JÚNIOR, W. Software AgroEstat - Sistema de análises estatísticas de ensaios agronômicos. Jaboticabal, Universidade Estadual Paulista, 2009 .

BATAGLIA, O.C.; FURLANI, A.M.C.; TEIXEIRA, J.P.F.; FURLANI, P.R. \& GALLO, J.R. Métodos de análise química de plantas. Campinas, Instituto Agronômico de Campinas, 1983. 48p. (Boletim Técnico, 78)

BIDWELL, S.D.; WOODROW, I.E.; BATIANOFF, G.N. \& SOMMER-KNUDSEN, J. Hyperaccumulation of manganese in the rainforest tree Austromystus bidwillii (Mirtaceae) from Queensland, Australia. Funct. Plant Biol., 29:899-905, 2002.

BROWN, P.H.; GRAHAM, R.D. \& NICHOLAS, D.J.D. The effect of manganese and nitrate supply on the levels of phenolics and lignin in young wheat plants. Plant Soil 81, 437-440, 1984.

CRANE, J.H. Tropical fruits. Gainesville, Institute of Food and Agricultural Science, University of Florida, 1998. v.1. CD ROM

DUCIC, T. \& POLLE, A. Transport and detoxification of manganese and copper in plants. Braz. J. Plant Physiol., 17:103-112, 2005

FOY, C.D.; CHANEY, R. L. \& WHITE, M.C. The physiology of metal toxicity in plants. Ann. Rev. Plant Physiol., 29:511566,1978 .

FURLANI, P.R. Hydroponic vegetable production in Brazil. Acta Hortic., 2:777-778, 1999

GRAHAM, R.D.; HANNAM, R.J. \& UREN, N.C. Manganese in soils and plants. Dordrecht, Kluwer Academic Publishers, 1988. 344p.

GRAHAM, R.D. \& ROVIRA, A.D. A role for manganese in the resistance of wheat plants to take-all. In: HUMPHRIES, J.M.; STANGOULIS, J.C.R. \& GRAHAM, R.D. Manganese. 12. Handbook of plant nutrition, 2006.p.351374.

GRAHAM, R.D. \& WEBB, M.J. Micronutrients and disease resistance and tolerance in plants. In: MORTVEDT, J.J.; COX, F.R.; SHUMAN, L.M. \& WELCH, R.M., eds. Micronutrients in Agriculture. Madison, Soil Science Society of America, 1991. p.333-339.

HUBER, D.M. \& KEELER, R.R. Alteration of wheat peptidase activity after infection with powdery mildew. In: HUMPHRIES, J.M.; STANGOULIS, J.C.R. \& GRAHAM, R.D. Manganese. 12. Handbook of plant nutrition, p.351$374,2006$.

LEAL, R.M. Adubação nitrogenada da caramboleira para pomar em implantação. Jaboticabal, Universidade Estadual Paulista, 2006. 53p. (Tese de Doutorado)

MALAVOLTA, E. Manual de nutrição mineral de plantas. São Paulo, Agronômica Ceres, 2006. 638p. 
MALAVOLTA, E.; VITTI, G.C. \& OLIVEIRA, S.A. Avaliação do estado nutricional das plantas: Princípios e aplicações. 2.ed. Piracicaba, Potafos, 1997. 319p.

MEMON, A.R.; HINO, M.; HARA, K. \& YATAZAWA, M. Microdistribution of manganese in the leaf tissues of different plant species as revealed by x-ray microanalyzer. Physiol. Plant., 53:225-232, 1981.

MORONI, J.S.; SCOTT, B.J. \& WRATTEN, N. Differential tolerance of high manganese among rapeseed genotypes. Plant Soil, 253:507-519, 2003.

PRADO, R.M. Efeitos da calagem no desenvolvimento, no estado nutricional e na produção de frutos da goiabeira e da caramboleira. Jaboticabal, Universidade Estadual Paulista, 2003. 68p. (Tese de Doutorado)

PRADO, R.M. \& NATALE, W. A calagem na nutrição e no desenvolvimento do sistema radical da caramboleira. $R$. Ci.. Agrovet., 3:3-8, 2004.

PRADO, R.M. \& NATALE, W. Effect of liming on the mineral nutrition and yield of growing guava trees in a typic hapludox soil. Comm. Soil Sci. Plant Anal., 39:2191-2204, 2008.

RAIJ, B.van; ANDRADE, J.C.; CANTARELLA, H. \& QUAGGIO, J.A. Análise química para avaliação da fertilidade de solos tropicais. Campinas, Instituto Agronômico de Campinas, 2001. 285p.

ROUT, G.R.; SAMANTARAY, S. \& DAS, P. Studies on differential manganese tolerance of mung bean and rice genotypes in hydroponic culture. Agronomie, 21:725-733, 2001.
ROZANE, D.E.; PRADO, R.M.; FRANCO, C.F. \& NATALE, W. Eficiência de absorção, transporte e utilização de macronutrientes por porta-enxertos de caramboleira, cultivados em soluções nutritivas. Ci. Agrotec., 31:10201026, 2007.

SADASIVAN, T.S. Effect of mineral nutrients on soil microorganisms and plant disease. In: HUMPHRIES, J.M.; STANGOULIS, J.C.R. \& GRAHAM, R.D. Manganese. 12. Handbook of plant nutrition, p.351-374, 2006.

SHARMA, C.P. Plant micronutrients. Lucknow, Lucknow University, 2006. 265p.

SILVA, H.; SILVA, A.Q.; CAVALCANTI, A.T. \& MALAVOLTA, E. Composição mineral das folhas de algumas fruteiras do Nordeste. In: CONGRESSO BRASILEIRO DE FRUTICULTURA, 7., Florianópolis, 1984. Anais... Florianópolis, EMPASC/SBF, 1984. v.1. p.320-325.

UDEL'NOVA, T.M.; BOICHENKO, E.A. \& KARYAKIN, A.V Polyvalent metals in chloroplasts. Fiziol. Rast., 23:115409, 1976.

YAN, S.L.; TSAY, C.C. \& CHEN, Y.R. Isolation and characterization of phytochelatin synthase in rice seedlings. Proc. Natl. Sci. Counc. Repub. China [B], 24:202207,2000 .

WHATLEY, F.R.; ORDIN, L. \& ARNON, D.I. Distribution of micronutrient metals in leaves and chloroplast fragments. Plant Physiol., 26:414-418, 1951. 
